\title{
Trajectory of migraine-related disability following long-term treatment with lasmiditan: results of the GLADIATOR study
}

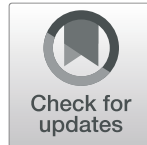

Richard B. Lipton ${ }^{1,2}$, Louise Lombard ${ }^{3}$, Dustin D. Ruff ${ }^{3}$, John H. Krege ${ }^{3}$, Li Shen Loo ${ }^{3 *}$, Andrew Buchanan ${ }^{3}$, Thomas E. Melby ${ }^{4}$ and Dawn C. Buse ${ }^{2}$

\begin{abstract}
Background: Migraine is recognized as the second leading cause of disability globally. Lasmiditan is a novel, selective serotonin $5-\mathrm{HT}_{1 \mathrm{~F}}$ receptor agonist developed for acute treatment of migraine. Here we analyzed effects of lasmiditan on migraine disability assessed with the Migraine Disability Assessment (MIDAS) scale for interim data from a long-term safety study.

Methods: Completers of two single-attack parent studies were offered participation in the 1 year GLADIATOR study, that randomized participants to treatment with lasmiditan $100 \mathrm{mg}$ or $200 \mathrm{mg}$ taken as needed for migraine attacks of at least moderate severity. Changes in MIDAS were modeled using a mixed model repeated measures analysis.

Results: The sample included 1978 patients who received $\geq 1$ lasmiditan dose and were followed for a median of 288 days. Baseline mean MIDAS scores for the lasmiditan 100-mg and 200-mg groups were 29.4 and 28.9, respectively, indicating severe migraine-related disability. Relative to baseline, MIDAS total scores were significantly lower at 3, 6, 9, and 12 months for both dose groups. At 12 months, changes in MIDAS scores were -12.5 and -12.2 for lasmiditan $100 \mathrm{mg}$ and $200 \mathrm{mg}$, respectively, with $49 \%$ and $53 \%$ of patients, respectively, achieving at least a $50 \%$ decrease in MIDAS total score. Statistically significant improvements were also seen for work and/or school absenteeism and presenteeism, monthly headache days, and mean headache pain intensity at all time points up to 1 year. Findings for patients who completed all visits versus those dropping out early were similar. Responses were generally similar for the lasmiditan $100 \mathrm{mg}$ or $200 \mathrm{mg}$ doses, between subgroups defined based on the number of baseline monthly migraine attacks ( $\leq 5$ vs. $>5$ ), and also between subgroups defined by pain-free response (yes/no) during initial attacks.
\end{abstract}

Conclusions: Long-term treatment with lasmiditan was associated with significant reductions in migraine-related disability, including both work or school absenteeism and presenteeism. The similarity of responses in completers and those who dropped out suggests that selective attrition does not account for the improvements. Benefits were significant at 3 months and maintained through 12 months.

Trial registration: clinicaltrials.gov NCT02565186; first posted October 1, 2015.

Keywords: Migraine, Serotonin, 5-HT 1 F agonist, Ditan, MIDAS, Disability, Function, Presenteeism, Absenteeism

\footnotetext{
*Correspondence: loo_li_shen@lilly.com

Previous presentation: Some of the data herein were presented at the 17 th Biennial Migraine Trust International Symposium (MTIS), September 6-9, 2018, London, UK (Lipton et al., Cephalalgia 2018; 38(2018): Abstract MTIS2018-169. https:/journals.sagepub.com/doi/full/10.1177/0333102418801648).

${ }^{3}$ Eli Lilly and Company, Indianapolis, IN, USA

Full list of author information is available at the end of the article
}

(C) The Author(s). 2020 Open Access This article is distributed under the terms of the Creative Commons Attribution 4.0 International License (http://creativecommons.org/licenses/by/4.0/), which permits unrestricted use, distribution, and reproduction in any medium, provided you give appropriate credit to the original author(s) and the source, provide a link to the Creative Commons license, and indicate if changes were made. 


\section{Background}

Migraine is a common and disabling disorder, affecting about $12 \%$ of the US population overall and $17 \%$ of women, with the highest prevalence between the ages of 18 and 55 [1-3]. Migraine is also highly prevalent and is recognized as the second leading cause of disability globally [4], and as the foremost cause of years lived with disability in people aged 15 to 49 [5].

Lasmiditan is an oral, selective $5-\mathrm{HT}_{1 \mathrm{~F}}$ receptor agonist indicated for the acute treatment of migraine. Lasmiditan is centrally penetrant and evidence suggests that lasmiditan exerts its therapeutic effects in the treatment of migraine by decreasing neuropeptide release and inhibiting pain pathways, potentially including both the trigeminal nerve innervation of the meningeal artery and in the trigeminocervical complex [6]. Lasmiditan lacks the vasoconstrictor activity which arises from the 5$\mathrm{HT}_{1 \mathrm{~B}}$ effects of triptans [6-10].

Two completed placebo-controlled Phase 3 studies assessed lasmiditan for the acute treatment of migraine: SAMURAI ( $N=1856$, ClinicalTrials.gov identifier: NCT02439320) and SPARTAN ( $N=2583$; NCT02605174) $[11,12]$. The studies were similarly designed, double-blind, and placebo-controlled, with participants randomized to treat a single migraine attack with oral lasmiditan $(50 \mathrm{mg}$ [SPARTAN only], $100 \mathrm{mg}$, or $200 \mathrm{mg}$ ) or placebo. In both of those studies, all doses of lasmiditan were significantly more effective than placebo based on the primary endpoint, pain freedom at $2 \mathrm{~h}$ postdose, and the key secondary endpoint, freedom from the patient-designated most bothersome symptom at $2 \mathrm{~h}$ postdose. Lasmiditan was generally safe and well tolerated, with no deaths and few serious adverse events reported [13].

The GLADIATOR study is a prospective, randomized, open-label, Phase 3 study designed to assess the long-term safety of lasmiditan with inclusion of efficacy measures, including migraine disability. Participants were randomized to lasmiditan $100 \mathrm{mg}$ and $200 \mathrm{mg}$ for the treatment of multiple migraine attacks for up to 1 year. Patients in the current analysis had previously completed one of two Phase 3 single-attack pivotal efficacy studies [11, 12].

Data assessing the interim efficacy and safety and tolerability of lasmiditan in GLADIATOR have been reported previously, including overall data for MIDAS total score and headache days [14]. Specifically, at baseline, mean (Migraine Disability Assessment) MIDAS score was approximately 29 , indicating, on average, severe migraine disability. Mean MIDAS total scores and number of days with headache decreased significantly from baseline at all timepoints for both lasmiditan treatment arms. In the present analyses of the same interim dataset, we further assessed changes in MIDAS total score, mean headache days, and average headache pain intensity across baseline patient characteristics and response subgroups, and assessed changes in absenteeism and presenteeism in the overall population.

\section{Methods \\ Study design and participants}

Patients who completed the pivotal efficacy studies (SAMURAI or SPARTAN) were potentially eligible to participate in the long-term safety study (GLADIATOR). Patients had episodic migraine, defined as 3-8 attacks/ month and $<15$ monthly headache days at baseline, and fulfilled ICHD-2 criteria 1.1 or 1.2.1 for migraine with or without aura [15]. These studies included patients with cardiovascular risk factors according to American College of Cardiology/American Heart Association Task Force on Practice Guidelines [16], including age, total and high-density lipoprotein cholesterol, systolic blood pressure, diabetes, and current smoking status. SPARTAN did not exclude patients with uncontrolled hypertension, clinically significant arrhythmia, or known coronary artery disease, although these patients were excluded from SAMURAI.

The study design of GLADIATOR has been reported in detail previously [14] and is described in brief below. All participants provided written informed consent and confirmed that they were willing to complete an e-diary. The study was conducted in compliance with the International Council for Harmonization principles of Good Clinical Practice. Ethics review boards approved the study protocol and the informed consent form prior to study commencement. GLADIATOR was conducted at study sites in the United States, United Kingdom, and Germany.

\section{Study design}

Patients in GLADIATOR were randomized 1:1 to treatment with lasmiditan $100 \mathrm{mg}$ or $200 \mathrm{mg}$, stratified (yes or no) for use of concomitant migraine preventive medications. Because of an insufficient supply of the 100-mg dose in Europe, all patients at European study sites were assigned to lasmiditan $200 \mathrm{mg}$.

Patients were instructed to use lasmiditan as the first treatment for each new migraine attack within $4 \mathrm{~h}$ of pain onset, provided that pain was moderate or severe and not improving. If migraine pain did not improve within $2 \mathrm{~h}$, or if the pain resolved but recurred, a second dose of lasmiditan was allowed within $24 \mathrm{~h}$ of the first dose, as long as no other migraine medication had been used. Alternately, patients could take their own medication for rescue or recurrence within 2 to $24 \mathrm{~h}$ from first dose, although triptans, ergots, opioids, and barbiturates were not permitted within $24 \mathrm{~h}$ of lasmiditan administration. Patients were originally dispensed lasmiditan at up to 8 doses per month ( 24 doses for 3 month periods) in 
addition to doses remaining from the previous study period, with additional doses available upon request.

\section{Data collection and endpoints}

At the GLADIATOR screening visit, patients were trained on use of the e-diary and completed the MIDAS (see Additional file) [17, 18]. MIDAS is scored based on a 5-item questionnaire that measures lost time over the previous 3 months due to migraine in the domains of school and work, household work, and family, social, or non-work activities $[17,18]$. Two additional questions are included regarding the average number of headache days and average headache pain over the last 3 months; however, these do not contribute to the MIDAS total score. MIDAS has demonstrated reliability and validity $[17,18]$ and scores correlate with clinical judgement on the need for medical care [19].

Patients were instructed to use an e-diary to record the details of each migraine attack. Patients were asked to record migraine headache pain using the 4-point pain severity rating scale (none, mild pain, moderate pain, and severe pain) at 0 (predose), 0.5, 1, 2, 4, 24, and $48 \mathrm{~h}$ postdose [20]. Pain freedom was defined as a reduction in pain severity from mild, moderate, or severe at baseline to none at the summarized time point. Migrainerelated disability over the course of the attack was assessed with the e-diary question "How much is your migraine interfering with your normal activities" at 0 (predose), $0.5,1,2,4,24$, and $48 \mathrm{~h}$ postdose. The 4 response options were "not at all" (0), "mild interference" (1), "marked interference" (2), and "need complete bed rest" (3). Baseline monthly migraine attacks were per study personnel entry on the case report form.

Other assessments included change from baseline in MIDAS total score, number of days with headache over the past 3 months, and average headache pain intensity over the last 3 months at 1, 3, 6, 9, and 12 months. Absenteeism days (missed days at work or school, see Additional file) were assessed based on MIDAS question 1 and presenteeism days (days present at work or school with substantially impaired productivity) were assessed based on MIDAS question 2 at 1, 3, 6, 9, and 12 months.

Clinic visits occurred at 1, 3, 6, 9, and 12 months. For the purposes of these analyses, clinically meaningful change in MIDAS total score was defined as a 5-point decrease, per previous findings [21], and the proportion of patients with a $50 \%$ or greater reduction in MIDAS score was also assessed.

Patients could voluntarily withdraw from the study or could be removed from the study at the discretion of the investigator or sponsor at any time, with the primary reason for discontinuation noted.

\section{Statistical methods}

All analyses were performed on the MIDAS population, which included all patients with any MIDAS assessment post-baseline; the exception was the analysis of "interference with normal activities" during the course of each attack, which included all patients who took study medication and reported interference values at each time point.

MIDAS total score was calculated as the sum of the answers to the 5 questions on the MIDAS questionnaire. Scores were used to assign MIDAS grades as follows: Grade 1: $0-5=$ no or little disability; Grade II: $6-10=$ mild disability; Grade III: $11-20=$ moderate disability; Grade IV: $\geq 21$ = severe disability [18]. Total lost productive days were calculated as the sum of MIDAS question 1 and question 2. A sensitivity analysis was performed assessing total lost productive days in patients with total lost workplace productive days at baseline $>0$ (sensitivity analysis population), thus excluding patients who had no productive days to gain.

The impact of informative discontinuation on overall treatment response was assessed by comparing patients with a maximum of $1,2,3$, and 4 quarters of available data versus data for all patients.

Least squares mean MIDAS score changes were modeled using a mixed model repeated measures analysis that included terms for treatment, visit, subgroup, treatment-by-visit, subgroup-by-treatment; subgroup-byvisit; and subgroup-by-treatment-by-visit. Statistical analyses were performed using SAS Version 9.4 or higher (SAS Institute, Cary, North Carolina).

\section{Results}

\section{Patient characteristics and disposition}

Baseline demographic and disease characteristics are shown in Table 1 . In the overall MIDAS population, the average age was 43.2 years (range 18 to 79 years) and $85 \%$ of patients were women. The majority of the patients were white $(77.6 \%)$ and $49.1 \%$ of patients had $\geq 2$ cardiovascular risk factors. Twenty-two percent of the patients were taking a migraine preventive medication.

Of 2116 patients randomized, 1978 patients received at least 1 dose of lasmiditan (safety population), and 19,058 total migraine attacks were treated. The median time on study was 288 days (IQR, 98-363 days, $n=1834$ ). As of the data cut-off for this interim analysis, 814 (41.2\% of the safety population) patients had completed the 12 months of study; 141 (7.1\%) patients were still receiving treatment; and $1023(51.7 \%)$ patients had discontinued. The most common reason for discontinuation was patient request (21.8\%), followed by adverse event (12.8\%) and lost to follow-up (9.2\%). Safety and tolerability data, as well as data on overall efficacy have been reported previously [14].

\section{Migraine-related disability}

The mean MIDAS total score at baseline was approximately 29 , which is in the range of severe migraine 
Table 1 Baseline characteristics by lasmiditan dose for the GLADIATOR MIDAS population

\begin{tabular}{|c|c|c|}
\hline Parameter & $\begin{array}{l}\text { Lasmiditan } 100 \mathrm{mg} \\
(\boldsymbol{N}=974)\end{array}$ & $\begin{array}{l}\text { Lasmiditan } 200 \mathrm{mg} \\
(\boldsymbol{N}=1063)\end{array}$ \\
\hline Age, mean years (SD) & $42.8(12.3)$ & $43.6(12.4)$ \\
\hline Female, n (\%) & $828(85.0)$ & $904(85.0)$ \\
\hline Body mass index, kg/m² (SD) & $31.1(8.2)$ & $31.0(8.1)$ \\
\hline \multicolumn{3}{|l|}{ Race } \\
\hline White, n (\%) & $744(76.4)$ & $837(78.7)$ \\
\hline African American, n (\%) & $193(19.8)$ & $181(17.0)$ \\
\hline Other, $\mathrm{n}(\%)$ & $37(3.8)$ & $43(4.0)$ \\
\hline Duration of migraine, mean years (SD) & $18.8(12.8)$ & $18.8(12.9)$ \\
\hline Migraine attacks/month, mean $\mathrm{n}(\mathrm{SD})^{\mathrm{a}}$ & $5.2(1.8)$ & $5.2(1.8)$ \\
\hline Migraine with aura ${ }^{b, c}, n(\%)$ & $356(36.6)$ & $366(34.5)$ \\
\hline Migraine preventive medication use, n (\%) & $214(22.0)$ & $234(22.0)$ \\
\hline \multicolumn{3}{|l|}{ Patients with CV risk factors ${ }^{\mathrm{b}, \mathrm{d}}, \mathrm{n}(\%)$} \\
\hline$\geq 1$ & $814(83.6)$ & $852(80.2)$ \\
\hline$\geq 2$ & $482(49.5)$ & $519(48.8)$ \\
\hline \multicolumn{3}{|l|}{ MIDAS questionnaire } \\
\hline MIDAS total score ${ }^{\mathrm{e}}$, mean (IQR) & $29.4(15,36)$ & $28.9(15,35)$ \\
\hline Headache days in past 3 months, mean $(\mathrm{IQR})^{f}$ & $15.5(8,20)$ & $15.5(8,20)$ \\
\hline Severity of headache pain ${ }^{9}$, mean (IQR) & $7.4(7,8)$ & $7.3(6,8)$ \\
\hline
\end{tabular}

Abbreviations: $C A D$ coronary artery disease; $C V$ cardiovascular; IQR interquartile range; MIDAS Migraine Disability Assessment; $S D$ standard deviation

"Based on response to the question in migraine history section of the case report form "Frequency of migraine attacks (average) during the last three months." ${ }^{b}$ Data from parent study. 'Fulfilling ICHD criteria 1.2.1 for migraine with typical aura. ${ }^{d}$ Hypertension, hypercholesterolemia, smoking, obesity, diabetes mellitus, family history of CAD, men over 40 years of age, and postmenopausal women. ${ }^{e}$ Calculated as the sum of the answers to the 5 questions on the MIDAS questionnaire $\left(0-5=\right.$ little or no disability; $6-10=$ mild disability; $11-20=$ moderate disability; $\geq 21=$ severe disability; $>40=$ very severe disability). ${ }^{f \prime}$ On how many days in the past 3 months did you have a headache? (If a headache lasted more than 1 day, count each day)". " $"$ On a scale of 0 to 10 , on average how painful were these headaches? (where $0=$ no pain at all, and $10=$ pain as bad as it can be)"

disability (Table 2). Mean MIDAS total scores decreased significantly from baseline to months $3,6,9$, and 12 for both the lasmiditan $100 \mathrm{mg}$ and $200 \mathrm{mg}$ treatment groups (Table 2), with no significant differences between the dose groups (all $p>0.43$ ). Similarly, no significant differences between lasmiditan dose groups were observed for the mean number of headache days (all $p>$ 0.31 ) and average headache pain over the last 3 months (all $p>0.46$; Table 2). To examine the effect of loss to follow-up at later time points, we assessed results separately for patients who completed a maximum of 3, 6, 9, and 12 months of study. Findings were similar to those for the whole population in each analysis when assessed by MIDAS total score (Fig. 1) or by headache days or headache pain (Additional file 1: Tables S1 and S2), indicating that the observed response was not broadly impacted by attrition.

For the overall population, we also assessed the impact of lasmiditan treatment on absenteeism and presenteeism. For absenteeism, days absent from work or school in the last 3 months decreased from a baseline mean of 3.1 and 3.2 to a mean of 1.9 and 1.6 at 12 months for the lasmiditan 100-mg and 200-mg dose groups, respectively; reductions were statistically significant at all time points (Table 3). For presenteeism, days present at work or school with at least $50 \%$ reduced productivity decreased from a baseline mean of 6.3 and 6.2 to a mean of 3.5 and 3.0 at 12 months for the lasmiditan $100-\mathrm{mg}$ and 200-mg groups, respectively; reductions were statistically significant at all time points (Table 3 ).

We assessed changes in total lost productive work days by summing changes in presenteeism and absenteeism. In the overall population, the mean decrease in lost productive days was significant by 3 months and remained significant through 12 months, with a mean improvement in lost productivity of up to $38 \%$ following 1 year of lasmiditan treatment (Table 3). Absenteeism contributed about a third and presenteeism contributed the remaining two-thirds of the total productive days gained. Summing absenteeism and presenteeism gains over a year in the overall population, treatment with lasmiditan was associated with an average annual improvement of up to 12 productive days. Findings were similar in a sensitivity analysis analyzing the subgroup of patients with total lost productive days at baseline $>0$ (lasmiditan $100 \mathrm{mg}, n=783$, lasmiditan $200 \mathrm{mg}, n=893$ ), with improvements of up to $42 \%$ following 1 year of lasmiditan treatment. A total of 16 productive days were gained on average in the sensitivity analysis population. 
Table 2 Overall change from baseline in MIDAS total score, headache days, headache pain, and number of treated attacks for patients who completed all 4 quarters of treatment

\begin{tabular}{|c|c|c|c|c|c|}
\hline & & Lasmiditar & $\mathrm{mg}(n=974)$ & Lasmidita & $\mathrm{mg}(n=1063)$ \\
\hline & & Change $\mathrm{fr}$ & & Change fi & \\
\hline & & LS mean & $\%$ change in LS mean & LS mean & $\%$ change in LS mean \\
\hline MIDAS Total Score & $\mathrm{BL}$, mean ${ }^{\mathrm{a}}$ & 29.4 & & 28.9 & \\
\hline & Month 3 & -7.7 & -26.3 & -7.0 & -24.3 \\
\hline & Month 6 & -9.8 & -33.5 & -9.2 & -31.9 \\
\hline & Month 9 & -11.0 & -37.6 & -10.1 & -34.9 \\
\hline & Month 12 & -12.5 & -42.6 & -12.2 & -42.2 \\
\hline Headache Days, past 3 months $s^{b, c}$ & $\mathrm{BL}$, mean & 15.5 & & 15.5 & \\
\hline & Month 3 & -3.5 & -22.6 & -3.9 & -24.8 \\
\hline & Month 6 & -4.5 & -28.7 & -4.1 & -26.1 \\
\hline & Month 9 & -5.2 & -33.7 & -5.7 & -36.7 \\
\hline & Month 12 & -5.7 & -36.8 & -6.0 & -38.8 \\
\hline Average headache pain intensity, $\mathrm{d}$ & $\mathrm{BL}$, mean & 7.4 & & 7.3 & \\
\hline & Month 3 & -0.4 & -5.4 & -0.4 & -5.7 \\
\hline & Month 6 & -0.7 & -9.1 & -0.7 & -9.0 \\
\hline & Month 9 & -0.8 & -10.4 & -0.9 & -11.9 \\
\hline & Month 12 & -1.1 & -15.1 & -1.2 & -16.6 \\
\hline Number of treated attacks, past 3 months ${ }^{e}$ & & Lasmiditaı & $\mathrm{mg}$ & Lasmidita & $\mathrm{mg}$ \\
\hline & & $\mathrm{N}$ & Mean & $\mathrm{N}$ & Mean \\
\hline & Month 3 & 326 & 6.0 & 320 & 6.0 \\
\hline & Q2 & 312 & 5.0 & 296 & 4.9 \\
\hline & Q3 & 303 & 4.4 & 298 & 4.3 \\
\hline & Q4 & 336 & $3.7^{* *}$ & 331 & $3.4^{* *}$ \\
\hline
\end{tabular}

Abbreviations: $B L$ baseline; $L S$ mean = least squares mean

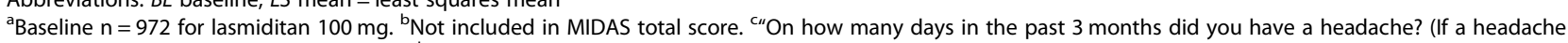
lasted more than 1 day, count each day)" dScale 1-10. "Data shown for patients who completed all 4 quarters. *All changes from baseline significant at $p<0.001$.

** $p$-values from paired t-tests vs 1 st quarter

Clinically meaningful improvements in MIDAS total score were also assessed over time. For at least a 5-point decrease from baseline, the proportion of responders increased steadily from $>53 \%$ at 3 months to $\geq 70 \%$ at 12 months. The proportion with at least a $50 \%$ decrease in MIDAS total score from baseline increased steadily from $\geq 30 \%$ at 3 months to $\geq 49 \%$ at 12 months (Fig. 2). Responses were generally similar in the 2 dose groups across the different cutoffs. In addition, the proportions of patients with $50 \%$ and $100 \%$ improvements from baseline in migraine-related total lost workplace productivity were assessed. At 12 months, up to $56 \%$ of patients had at least $50 \%$ reduction in total lost productive days, and up to $20 \%$ had a $100 \%$ reduction in total lost productive days due to migraine (Fig. 3).

\section{Migraine-related functional impairment over the course of the attack}

In addition to assessing long-term migraine disability by the MIDAS instrument, the degree of difficulty in performing activities of daily living was assessed over the first $48 \mathrm{~h}$ post-dosing. Across both dose groups, the proportion of patients who reported being able to function normally for the first treated attack was $64.5 \%$ by $4 \mathrm{~h}$ and $85.7 \%$ by $24 \mathrm{~h}$ post-lasmiditan dosing (Table 4 ). Similar improvements were observed from attack 1 through attack 20.

\section{Subgroup analysis by baseline MIDAS Total score severity} Subgroup analysis was performed comparing MIDAS disability $<21$ vs. $\geq 21$ at baseline. As shown in Table 5, there were notable differences in improvement in MIDAS total score, absenteeism, and presenteeism, and in headache days, between MIDAS severity subgroups at baseline. Decreases from baseline were generally noted in all parameters in both subgroups and with both lasmiditan doses. The decrease from baseline was greater in the subgroup with greater baseline disability based on MIDAS total score (visit-by-subgroup interaction term $p<0.001)$, absenteeism $(p<0.001)$, presenteeism $(p<$ 

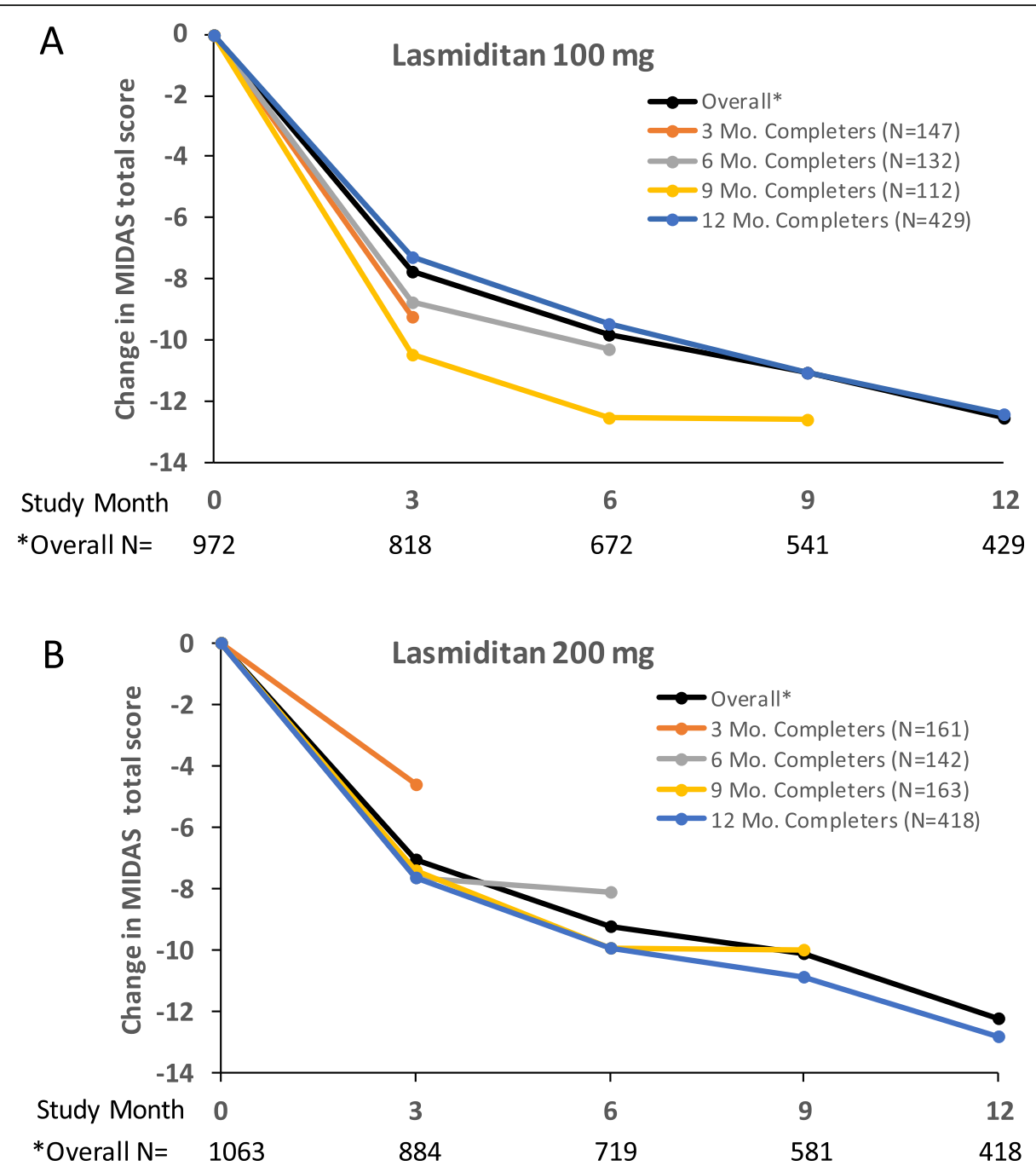

Fig. 1 Completer analysis showing MIDAS total score overall and for patients who completed a maximum of 3, 6, 9, or 12 months of study for a) Lasmiditan $100 \mathrm{mg}$ and $\mathbf{b}$ ) Lasmiditan $200 \mathrm{mg}$. Abbreviations: Mo. = month. Note that $\mathrm{N}$ within completer subgroups remained nearly constant (within 2 patients) across relevant timepoints

$0.001)$, and headache days $(p=0.017)$. The differences in response between baseline disability subgroups appeared to be greatest for absenteeism and presenteeism both at baseline and during treatment (Table 4).

\section{Response by number of monthly migraine attacks at baseline}

The mean number of monthly migraine attacks at baseline was 5.2 (Table 1). In order to examine whether the frequency of migraine attacks at baseline affected MIDAS reductions, we assessed response for patients with baseline frequency of attacks of $\leq 5$ or $>5$ per month. At baseline, the mean MIDAS total scores were approximately 26.4 for the $\leq 5$ attacks/month group and 33.5 for the $>5$ attacks/month group. Mean MIDAS total scores decreased significantly from baseline at all time points for each dose group in both subgroups (all comparisons, $p<0.001$ vs. baseline; Fig. $4 \mathrm{a}$ and b). Similar findings were seen for number of headache days (Additional file 1: Table S3) and for headache pain (except average headache pain for the $>5$ subgroup, 200-mg dose group at 3 months, $p=0.004$; Additional file 1 : Table S4). Subgroup analysis for number of monthly attacks showed a greater decrease from baseline over time in the $>5$ than in the $\leq 5$ subgroup (visit-by-subgroup interaction term $p<0.001)$.

\section{Subgroup analyses by pain-free response at 2 hours}

To examine whether pain-free responses at $2 \mathrm{~h}$ for the first few treated attacks predicted change in MIDAS with lasmiditan treatment, we categorized participants into two groups, those who achieved pain freedom $2 \mathrm{~h}$ postdose and those who did not for the first migraine attack, and for 2 of the first 3 migraine attacks. 
Table 3 Change from baseline in MIDAS absenteeism (days), presenteeism (days), and total lost productive days

\begin{tabular}{|c|c|c|c|c|c|}
\hline & & Lasmiditan & $(n=972)$ & Lasmiditar & $(n=1063)$ \\
\hline & & Change fro & & Change fr & \\
\hline & & LS mean* & $\%$ change in mean & LS mean & $\%$ change in mean \\
\hline Absenteeism (days) & $\mathrm{BL}$, mean ${ }^{\mathrm{a}}$ & 3.1 & & 3.2 & \\
\hline & Month 3 & -0.6 & -20.2 & -0.8 & -25.1 \\
\hline & Month 6 & -0.9 & -29.2 & -0.9 & -29.5 \\
\hline & Month 9 & -1.0 & -32.4 & -1.0 & -30.7 \\
\hline & Month 12 & -1.0 & -32.4 & -1.2 & -38.6 \\
\hline Presenteeism (days) & $\mathrm{BL}$, mean ${ }^{\mathrm{a}}$ & 6.3 & & 6.2 & \\
\hline & Month 3 & -1.5 & -24.1 & -1.4 & -21.7 \\
\hline & Month 6 & -2.1 & -32.4 & -1.8 & -29.3 \\
\hline & Month 9 & -2.3 & -36.1 & -1.8 & -29.6 \\
\hline & Month 12 & -2.6 & -40.3 & -2.3 & -37.2 \\
\hline Total lost productive days ${ }^{\mathrm{b}}$ & $\mathrm{BL}$, mean & 9.4 & & 9.4 & \\
\hline & Month 3 & -2.2 & -23.4 & -2.2 & -23.4 \\
\hline & Month 6 & -3.0 & -31.9 & -2.8 & -29.8 \\
\hline & Month 9 & -3.3 & -35.1 & -2.8 & -29.8 \\
\hline & Month 12 & -3.6 & -38.3 & -3.5 & -37.2 \\
\hline
\end{tabular}

Abbreviations: $B L$ baseline; $L S$ mean least squares mean

*All changes from baseline significant at $p<0.001$

${ }^{a}$ Calculated as the sum of MIDAS question 1 (absenteeism from work or school) and question 2 (presenteeism at work or school). ${ }^{b}$ Includes patients with 0 total lost productive days at baseline

For the lasmiditan 100-mg and 200-mg treatment groups, 31.7\% (292/920) and 34.3\% (332/969) of patients, respectively, achieved pain-free response on their first treated attack in GLADIATOR. For subgroups based on pain-free response for the first migraine attack, baseline mean MIDAS total scores differed only slightly (approximately 27.8 for pain free at $2 \mathrm{~h}, 30.2$ for not pain free), and MIDAS total scores decreased significantly from baseline at all time points for each dose group in both subgroups (all comparisons, $p<0.001$ vs. baseline; Fig. 5a and b). Changes in MIDAS total scores over time were similar between the 2 subgroups. The findings were generally similar for these subgroups for number of headache days (Additional file 1: Table S5), and also for headache pain (Additional file 1: Table S6).

For pain-free response at $2 \mathrm{~h}$ in at least 2 of the first 3 treatment attempts, 28.3\% (198/699) and 29.9\% (220/ 736) of patients treated with lasmiditan $100 \mathrm{mg}$ and 200 mg respectively, achieved positive response. Baseline mean MIDAS values differed somewhat (approximate means 27.1 and 31.7, respectively) between patients with pain-free response in at least 2 of 3 attacks vs those who did not. MIDAS total scores decreased significantly from baseline at all timepoints for each dose group in both subgroups (all comparisons, $p<0.001$ vs. baseline; Fig. $5 \mathrm{c}$ and $\mathrm{d}$ ). Changes were also significant for number of headache days across dose groups for both subgroups (all comparisons, $p<0.001$ vs. baseline, Additional file 1:
Table S7), with no significant differences between doses. For average headache pain, changes from baseline were significant across dose groups at all timepoints in the not pain free for at least 2 of the first 3 attempts subgroup (all $p<0.05$, Additional file 1: Table S8); for the subgroup that was pain free at $2 \mathrm{~h}$ for at least 2 of the first 3 attempts, average headache pain decreased from baseline for both doses and at all time points. Statistical significance $(p<0.05)$ was achieved at 3 and 12 months for the lasmiditan 100-mg group and at 6, 9, and 12 months for the lasmiditan 200-mg dose group.

\section{Discussion}

Migraine imposes a significant burden on family, work, school, and social life, especially to those under age 55 . $[3,5]$ The MIDAS is a valid and reliable migrainerelated disability measure that is strongly correlated with clinical judgement of the severity of migraine and the need for healthcare services [22]. In the interim results from the GLADIATOR study, significant and increasing improvements in MIDAS total score and mean headache days were reported with intermittent use of lasmiditan for up to a year [14]. At baseline, patients had an average MIDAS score of 29 , representing a migraine population with severe migraine-related disability. Results from the present study demonstrate that decreases in MIDAS total scores were statistically significant for both lasmiditan doses by 3 months and that those benefits were 


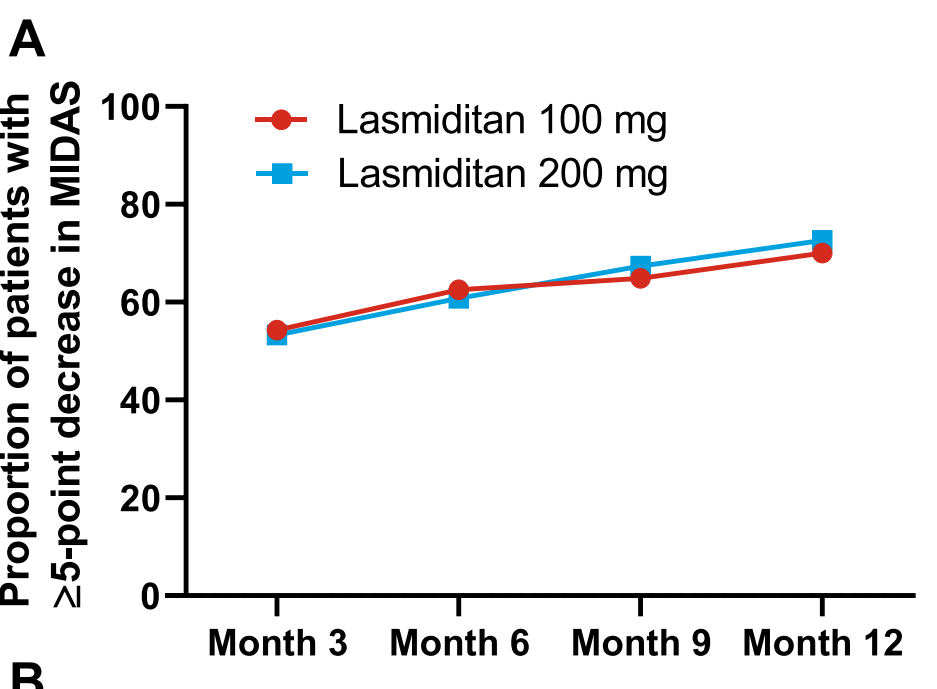

B

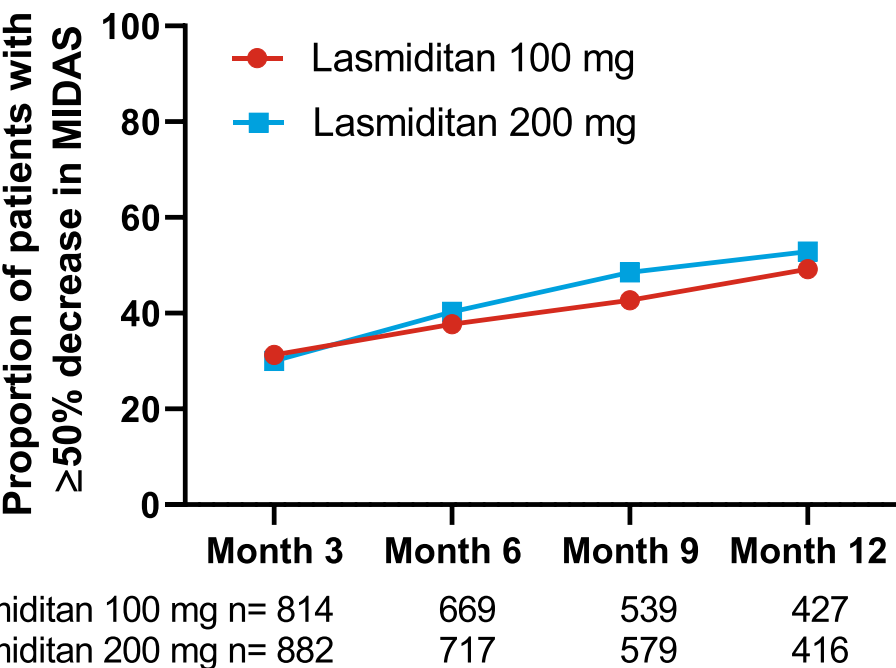

Fig. 2 Decreases from baseline in MIDAS total score of (a) $\geq 5$ points or $(\mathbf{b}) \geq 50 \%$

sustained from 3 through 12 months. Benefits were generally consistent across subgroups assessed by number of monthly attacks at baseline, pain-free response at $2 \mathrm{~h}$ on the first attempt, and pain-free response at $2 \mathrm{~h}$ on at least 2 of the first 3 attempts. The magnitude of MIDAS reduction was greater in persons with MIDAS scores $\geq 21$ compared to those with baseline scores of $<21$. Mean MIDAS total scores decreased with increasing duration in the study. In addition, a clinically meaningful response of at least a 5 -point decrease from baseline in MIDAS total score [21] was seen in a steadily increasing proportion of patients over time, reaching $\geq 70 \%$ across the 2 lasmiditan dose groups at 12 months.

In this study, MIDAS scores, headache days, and headache severity decreased significantly and progressively during treatment over a follow-up period of up to a year. Only limited data are available for MIDAS changes during treatment with acute medications for migraine. A study of sumatriptan plus naproxen showed a baseline MIDAS score of 28.7 and a follow-up MIDAS of 22.6 after 3 months of treatment. Similarly, a naproxen-only group showed a baseline of 27.9 and a follow-up MIDAS score of 24.1 after 3 months of treatment [23]. In a study of 62 Japanese migraine patients treated with triptans for 17 months, MIDAS score was 27.2 at baseline and 15.5 at endpoint $(p=.0002)$; however, headache days were similar at baseline (27.5) and at the end of study (23.4, $p=\mathrm{NS}$ ) [24]. Long-term safety studies provide some insight into the relative stability of migraine disease during treatment with triptans. For example, in a study of almotriptan for 12 months, the average number of headaches treated in month 1 was 2.39 and in month 12 was 2.37 [25]. In a one-year study of zolmitriptan nasal spray, the mean number of headaches treated per person across 90-day treatment periods ranged from 10.0 to 10.6 [26]. For frovatriptan, migraine days were 10.8 at 

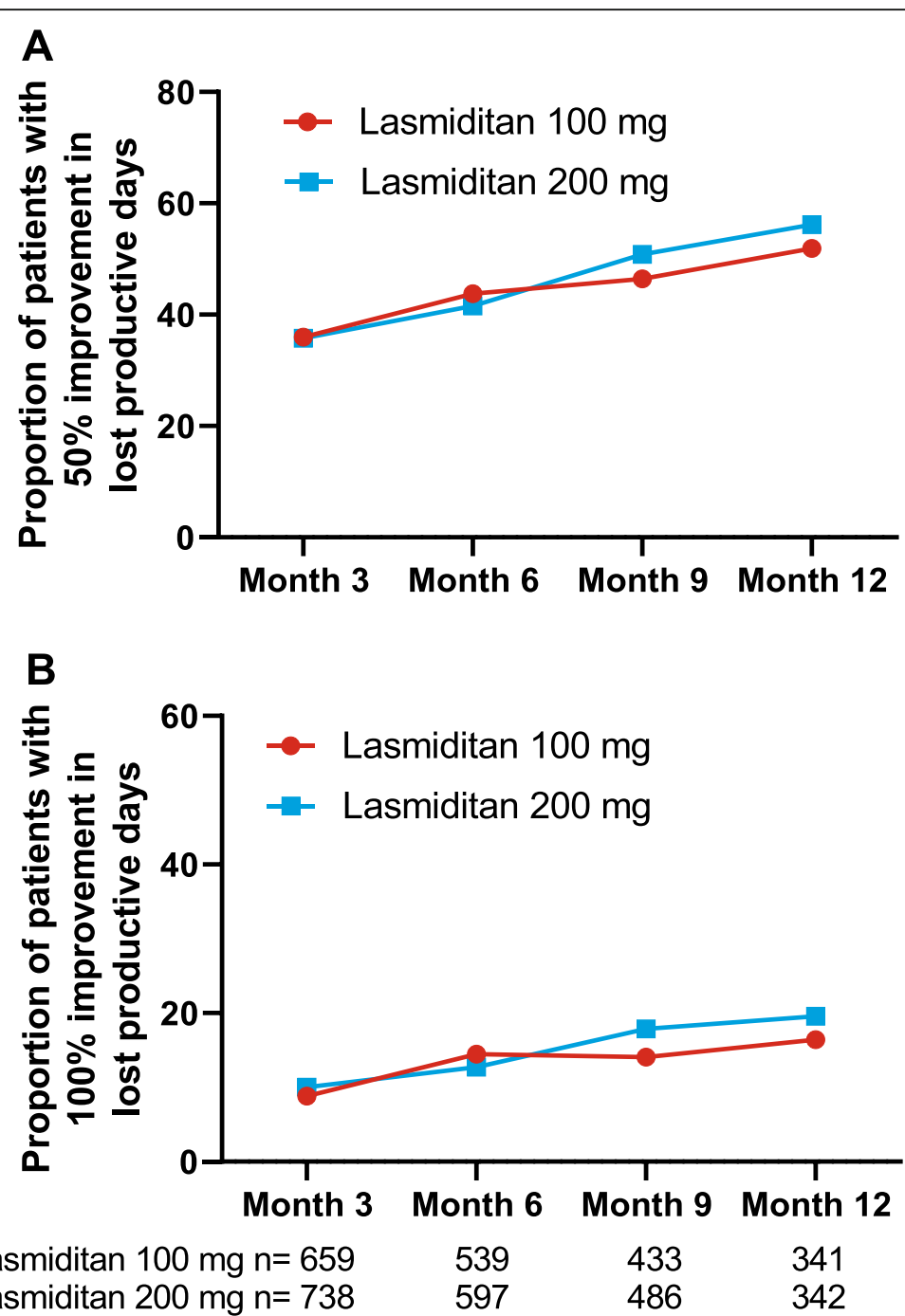

Fig. 3 Improvement from baseline in lost productive days of (a) $\geq 50 \%$ or (b) $100 \%$

baseline and 9.6 after 6 months of treatment [27]. Finally, in a rizatriptan study, mean monthly headache rate was $\sim 4.2$ during months $1-3$ and $~ 3.3$ during months 10-12 [28]. Thus while mean migraine-related disability and headache days decreased for patients receiving lasmiditan in the present study, treatment with triptans results in variable effects on migraine disability and a relatively stable number of migraine headache days at a population level. Migraine attack frequency may increase or decrease over time [29]. The decrease in headache days with lasmiditan treatment may represent a preventive effect of lasmiditan or may be a result of the natural history of the disease or some other unknown effect; in the absence of a placebo control arm in this long-term safety study, we cannot distinguish these possibilities.

In GLADIATOR, absenteeism decreased for both lasmiditan doses at all time points during treatment for up to a year. Additionally, presenteeism (continuing to work despite reduced effectiveness) also decreased significantly for both lasmiditan doses at all time points. These results indicate that lasmiditan may reduce both complete loss of work days and days with impaired functioning.

Workplace productivity improvements following successful migraine treatment can have a substantial impact on lives of people with migraine. Total workplace productivity gains can be estimated by summing presenteeism and absenteeism gains [30-32]. Treatment with lasmiditan was associated with an average reduction in lost productivity of up to 12 days per year, which equates to approximately $\$ 2700$ per person per year based on an average US hourly wage of $\sim \$ 28$ [33].

In a comparison of those with higher versus lower disability (baseline total MIDAS total score moderate $<21$ vs. severe $\geq 21$ ), both subgroups showed improvements in total MIDAS score, headache days, headache pain, 
Table 4 Observed case analysis of patients free of disability at specified times post-dose for selected attacks

\begin{tabular}{|c|c|c|c|c|}
\hline & Time point & $\begin{array}{l}\text { Lasmiditan } 100 \mathrm{mg}^{\mathbf{a}} \\
\mathrm{n} / \mathrm{N}(\%)\end{array}$ & $\begin{array}{l}\text { Lasmiditan } 200 \mathrm{mg}^{\mathbf{a}} \\
\mathrm{n} / \mathrm{N}(\%)\end{array}$ & $\begin{array}{l}\text { Overalla } \\
\mathrm{n} / \mathrm{N}(\%)\end{array}$ \\
\hline \multirow[t]{7}{*}{ Attack 1} & Baseline & 16/931 (1.7) & 26/963 (2.7) & $42 / 1894(2.2)$ \\
\hline & $0.5 \mathrm{~h}$ & 60/797 (7.5) & $53 / 828$ (6.4) & $113 / 1625$ (7.0) \\
\hline & $1 \mathrm{~h}$ & 176/814 (21.6) & 183/846 (21.6) & $359 / 1660$ (21.6) \\
\hline & $2 \mathrm{~h}$ & $327 / 847$ (38.6) & $341 / 869$ (39.2) & $668 / 1716$ (38.9) \\
\hline & $4 \mathrm{~h}$ & $385 / 585(65.8)$ & 429/677 (63.4) & $814 / 1262(64.5)$ \\
\hline & $24 \mathrm{~h}$ & $374 / 432$ (86.6) & 420/495 (84.8) & 794/927 (85.7) \\
\hline & $48 \mathrm{~h}$ & $365 / 414(88.2)$ & 436/504 (86.5) & $801 / 918$ (87.3) \\
\hline \multirow[t]{7}{*}{ Attack 5} & Baseline & $5 / 560(0.9)$ & $5 / 566(0.9)$ & 10/1126 (0.9) \\
\hline & $0.5 \mathrm{~h}$ & 28/477 (5.9) & 21/491 (4.3) & 49/968 (5.1) \\
\hline & $1 \mathrm{~h}$ & $80 / 484$ (16.5) & $89 / 510$ (17.5) & 169/994 (17.0) \\
\hline & $2 \mathrm{~h}$ & 189/505 (37.4) & $194 / 504(38.5)$ & $383 / 1009$ (38.0) \\
\hline & $4 \mathrm{~h}$ & 233/345 (67.5) & 249/372 (66.9) & $482 / 717(67.2)$ \\
\hline & $24 \mathrm{~h}$ & 232/271 (85.6) & 249/299 (83.3) & 481/570 (84.4) \\
\hline & $48 \mathrm{~h}$ & 243/271 (89.7) & 239/286 (83.6) & 482/557 (86.5) \\
\hline \multirow[t]{7}{*}{ Attack 10} & Baseline & 2/324 (0.6) & 4/298 (1.3) & 6/622 (1.0) \\
\hline & $0.5 \mathrm{~h}$ & $11 / 275$ (4.0) & 14/262 (5.3) & 25/537 (4.7) \\
\hline & $1 \mathrm{~h}$ & $41 / 281$ (14.6) & 48/263 (18.3) & $89 / 544(16.4)$ \\
\hline & $2 \mathrm{~h}$ & 85/285 (29.8) & 98/269 (36.4) & 183/554 (33.0) \\
\hline & $4 \mathrm{~h}$ & 109/172 (63.4) & 133/192 (69.3) & $242 / 364(66.5)$ \\
\hline & $24 \mathrm{~h}$ & 100/130 (76.9) & 116/140 (82.9) & 216/270 (80.0) \\
\hline & $48 \mathrm{~h}$ & 108/121 (89.3) & 116/138 (84.1) & $224 / 259(86.5)$ \\
\hline \multirow[t]{7}{*}{ Attack 15} & Baseline & 1/193 (0.5) & 0/174 (0) & 1/367 (0.3) \\
\hline & $0.5 \mathrm{~h}$ & 6/154 (3.9) & $6 / 145(4.1)$ & $12 / 299(4.0)$ \\
\hline & $1 \mathrm{~h}$ & 15/157 (9.6) & $25 / 146(17.1)$ & 40/303 (13.2) \\
\hline & $2 \mathrm{~h}$ & 43/172 (25.0) & $57 / 156(36.5)$ & $100 / 328(30.5)$ \\
\hline & $4 \mathrm{~h}$ & 54/97 (55.7) & $65 / 104(62.5)$ & $119 / 201$ (59.2) \\
\hline & $24 \mathrm{~h}$ & $57 / 69(82.6)$ & $81 / 90(90.0)$ & 138/159 (86.8) \\
\hline & $48 \mathrm{~h}$ & 63/76 (82.9) & 71/85 (83.5) & 134/161 (83.2) \\
\hline \multirow[t]{7}{*}{ Attack 20} & Baseline & 2/116 (1.7) & 0/108 (0) & 2/224 (0.9) \\
\hline & $0.5 \mathrm{~h}$ & $1 / 98(1.0)$ & $4 / 95(4.2)$ & 5/193 (2.6) \\
\hline & $1 \mathrm{~h}$ & 12/104 (11.5) & 17/92 (18.5) & 29/196 (14.8) \\
\hline & $2 \mathrm{~h}$ & 25/103 (24.3) & 36/94 (38.3) & 61/197 (31.0) \\
\hline & $4 \mathrm{~h}$ & 28/52 (53.8) & 40/59 (67.8) & 68/111 (61.3) \\
\hline & $24 \mathrm{~h}$ & $33 / 44(75.0)$ & 41/51 (80.4) & 74/95 (77.9) \\
\hline & $48 \mathrm{~h}$ & 35/42 (83.3) & 43/52 (82.7) & 78/94 (83.0) \\
\hline
\end{tabular}

Abbreviations: $\mathrm{n}=$ number of patients in category; $\mathrm{N}=$ number of patients with data available

Based on electronic diary question "How much is your migraine interfering with your normal activities." Response options were "not at all," "mild interference," "marked interference," and "need complete bed rest". Data shown for "not at all" (no disability). Analysis of "interference with normal activities" during the course of each attack included all patients who took study medication and reported interference values at each time point

absenteeism, and presenteeism. However, a greater response to lasmiditan was generally seen for patients with MIDAS disability scores rated as severe at baseline. Notably, the MIDAS total score directly includes measures of absenteeism and presenteeism scores (along with lost time in household work as well as family, social, and leisure activities), but not the scores for headache days and headache pain. This is likely to have impacted the results for absenteeism and presenteeism in the $\geq 21$ baseline MIDAS total score subgroup since the markedly higher (approaching 3-fold) baseline scores for absenteeism and presenteeism allow greater range for 
Table 5 Change from baseline in MIDAS response by baseline MIDAS disability severity ( $<21 \mathrm{vs.} \geq 21)$

\begin{tabular}{|c|c|c|c|c|c|c|c|c|c|}
\hline & & \multicolumn{4}{|c|}{ MIDAS total $<21$ at baseline } & \multicolumn{4}{|c|}{ MIDAS total $\geq 21$ at baseline } \\
\hline & & \multicolumn{2}{|c|}{$\begin{array}{l}\text { Lasmiditan } 100 \mathrm{mg} \\
(n=418)\end{array}$} & \multicolumn{2}{|c|}{$\begin{array}{l}\text { Lasmiditan } 200 \mathrm{mg} \\
(n=465)\end{array}$} & \multicolumn{2}{|c|}{$\begin{array}{l}\text { Lasmiditan } 100 \mathrm{mg} \\
(n=554)\end{array}$} & \multicolumn{2}{|c|}{$\begin{array}{l}\text { Lasmiditan } 200 \mathrm{mg} \\
(n=598)\end{array}$} \\
\hline & & LS mean & $\begin{array}{l}\% \text { change in } \\
\text { mean }\end{array}$ & LS mean & $\begin{array}{l}\% \text { change in } \\
\text { mean }\end{array}$ & LS mean & $\begin{array}{l}\% \text { change in } \\
\text { mean }\end{array}$ & LS mean & $\begin{array}{l}\% \text { change in } \\
\text { mean }\end{array}$ \\
\hline \multirow[t]{5}{*}{ MIDAS Total } & $\begin{array}{l}\text { Baseline, } \\
\text { mean }\end{array}$ & 13.8 & & 13.8 & & 41.1 & & 40.7 & \\
\hline & Month 3 & -0.6 & -4.2 & $-1.7^{* *}$ & -12.5 & $-13.3^{* *}$ & -32.3 & $-11.3^{* *}$ & -27.9 \\
\hline & Month 6 & $-1.9^{* *}$ & -13.9 & $-2.5^{* *}$ & -18.3 & $-16.1^{* *}$ & -39.1 & $-14.9^{* *}$ & -36.6 \\
\hline & Month 9 & $-2.6^{* *}$ & -18.9 & $-3.9^{* *}$ & -28.0 & $-17.8^{* *}$ & -43.3 & $-15.3^{* *}$ & -37.7 \\
\hline & Month 12 & $-4.1^{* *}$ & -29.7 & $-4.2^{* *}$ & -30.4 & $-19.3^{* *}$ & -47.0 & $-19.5^{* *}$ & -47.8 \\
\hline \multirow[t]{5}{*}{ Absenteesim } & $\begin{array}{l}\text { Baseline, } \\
\text { mean }\end{array}$ & 1.47 & & 1.67 & & 4.37 & & 4.38 & \\
\hline & Month 3 & -0.1 & -5.4 & $-0.4^{* *}$ & -22.2 & $-1.1^{* *}$ & -24.0 & $-1.2^{* *}$ & -26.3 \\
\hline & Month 6 & -0.1 & -6.1 & -0.2 & -12.0 & $-1.5^{* *}$ & -35.2 & $-1.6^{* *}$ & -35.4 \\
\hline & Month 9 & $-0.3^{*}$ & -17.7 & $-0.3^{*}$ & -19.8 & $-1.6^{* *}$ & -36.8 & $-1.5^{* *}$ & -35.2 \\
\hline & Month 12 & -0.2 & -10.2 & $-0.4^{*}$ & -22.2 & $-1.7^{* *}$ & -39.4 & $-2.0^{* *}$ & -45.2 \\
\hline \multirow[t]{5}{*}{ Presenteeism } & $\begin{array}{l}\text { Baseline, } \\
\text { mean }\end{array}$ & 2.77 & & 3.02 & & 9.00 & & 8.70 & \\
\hline & Month 3 & -0.02 & -0.7 & -0.2 & -7.6 & $-2.7^{* *}$ & -29.9 & $-2.3^{* *}$ & -26.0 \\
\hline & Month 6 & -0.1 & -4.7 & -0.3 & -9.6 & $-3.6^{* *}$ & -39.7 & $-3.1^{* *}$ & -35.6 \\
\hline & Month 9 & -0.3 & -10.5 & $-0.8^{* *}$ & -24.8 & $-3.9^{* *}$ & -43.1 & $-2.8^{* *}$ & -31.8 \\
\hline & Month 12 & $-0.6^{*}$ & -23.1 & $-0.6^{*}$ & -20.5 & $-4.1^{* *}$ & -45.4 & $-3.9^{* *}$ & -44.3 \\
\hline \multirow[t]{5}{*}{ Headache days ${ }^{\mathrm{a}}$} & $\begin{array}{l}\text { Baseline, } \\
\text { mean }\end{array}$ & 11.05 & & 10.92 & & 18.89 & & 19.14 & \\
\hline & Month 3 & $-2.7^{* *}$ & -24.7 & $-2.1^{* *}$ & -19.5 & $-4.1^{* *}$ & -21.7 & $-5.2^{* *}$ & -27.4 \\
\hline & Month 6 & $-2.8^{* *}$ & -25.0 & $-2.2^{* *}$ & -20.4 & $-5.8^{* *}$ & -30.8 & $-5.5^{* *}$ & -28.9 \\
\hline & Month 9 & $-3.7^{* *}$ & -33.6 & $-3.4^{* *}$ & -31.1 & $-6.4^{* *}$ & -34.1 & $-7.6^{* *}$ & -39.9 \\
\hline & Month 12 & $-4.6^{* *}$ & -41.2 & $-3.3^{* *}$ & -30.0 & $-6.6^{* *}$ & -34.9 & $-8.4^{* *}$ & -43.9 \\
\hline \multirow[t]{5}{*}{$\begin{array}{l}\text { Average headache pain } \\
\text { intensity }{ }^{a}\end{array}$} & $\begin{array}{l}\text { Baseline, } \\
\text { mean }\end{array}$ & 7.32 & & 7.14 & & 7.46 & & 7.49 & \\
\hline & Month 3 & $-0.4^{*}$ & -4.9 & $-0.4^{* *}$ & -5.9 & $-0.4^{* *}$ & -5.8 & $-0.4^{* *}$ & -5.6 \\
\hline & Month 6 & $-0.7^{* *}$ & -10.1 & $-0.6^{* *}$ & -8.0 & $-0.6^{* *}$ & -8.3 & $-0.7^{* *}$ & -9.9 \\
\hline & Month 9 & $-0.8^{* *}$ & -10.4 & $-1.0^{* *}$ & -14.1 & $-0.8^{* *}$ & -10.3 & $-0.8^{* *}$ & -10.0 \\
\hline & Month 12 & $-1.0^{* *}$ & -13.8 & $-1.2^{* *}$ & -16.7 & $-1.2^{* *}$ & -16.1 & $-1.3^{* *}$ & -17.0 \\
\hline
\end{tabular}

${ }^{*} p<.05 ;{ }^{* *} p<.001$. ${ }^{\text {Not }}$ included in MIDAS total score. Abbreviations: BL = baseline; LS mean = least squares mean; $\mathrm{n}=$ number of patients in subgroup

improvement due to treatment effects and to unrelated regression to the mean. These results show that patients treated with lasmiditan with either moderate or severe migraine-related disability on average appeared to have an improvement in their disability, with greater improvement in the severely disabled patients.

One factor that could contribute to the decrement in disability over time is a decrease in the frequency of attacks. In this study, headache days decreased significantly and progressively during treatment for up to a year; the mean number of migraine attacks treated with lasmiditan per patient per quarter decreased over time from 6.0 to 3.7 for lasmiditan $100 \mathrm{mg}$ and 6.0 to 3.4 for lasmiditan $200 \mathrm{mg}$ dose [14]. Another factor that could contribute to the overall improvements in disability could be reduced disability associated with each individual attack. In GLADIATOR, the proportion of patients with no disability increased over the course of the treated attack, with $64.5 \%$ reporting no disability $4 \mathrm{~h}$ post-treatment and $85.7 \%$ reporting no disability $24 \mathrm{~h}$ post-treatment. Reduced disability during each attack could also contribute to reduced presenteeism and absenteeism over time. Thus, both decrease in the frequency of attack and reduction in disability per attack likely contributed to the overall reduction in MIDAS over time. 


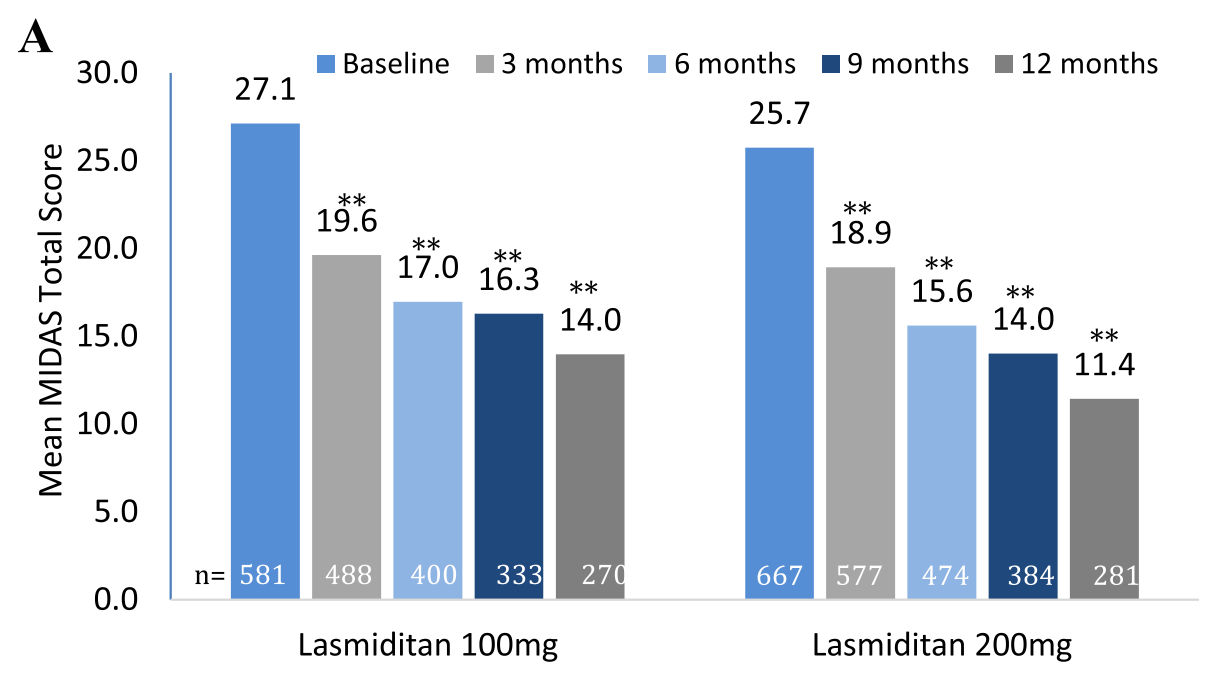

B

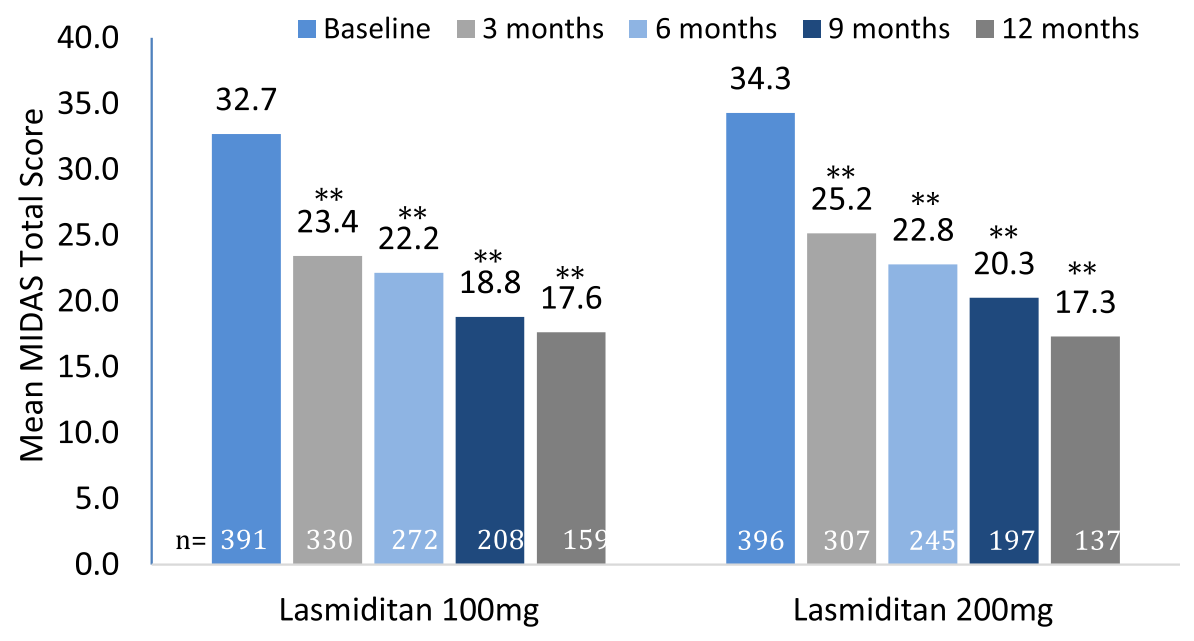

**P $<0.001$ vs. baseline; mixed model for repeated measures

There were no significant differences between the lasmiditan dose groups

Fig. 4 Mean MIDAS score by study month in subgroups defined by monthly migraine attacks at baseline (a) $\leq 5$ and (b) $>5$. ${ }^{* *} P<0.001$ vs. baseline; mixed model for repeated measures. There were no significant differences between the lasmiditan dose groups.

In longitudinal analyses such as these, it is important to evaluate the potential impact of loss to follow-up. If patients with a poorer treatment response are more likely to drop out, that could contribute to the decrement in disability over time. To assess this issue, we compared results in completers with those in patients who dropped out, an approach in line with the guidance from the National Academy of Science white paper on missing data in clinical trials [34]. Analyses of patients with a maximum of $3,6,9$, and 12 months of data showed similar results, suggesting that selective attrition did not have a major impact on our conclusions regarding reductions in disability.

Limitations of the present study include that it was an open-label design, and thus lacked a placebo control group for comparison. As a consequence, we cannot control for placebo effects or for regression to the mean. In addition, there was a somewhat higher rate of patient dropout $(51.7 \%)$ than seen in a 12 -month study of telcagepant (42.4\%) versus rizatriptan (35.1\%) [28], as well as earlier long-term studies of zolmitriptan [35] and almotriptan [25]. Discontinuation over time could result in retention of a sample for whom lasmiditan has greater efficacy, potentially resulting in accumulating reductions in MIDAS scores. However, analyses of patients with a maximum of $1,2,3$, and 4 available quarters of data showed similar results, suggesting that attrition was not an obvious contributor to our results. The validity of the 3-month MIDAS questionnaire has been evaluated against a daily diary. Although individuals may 


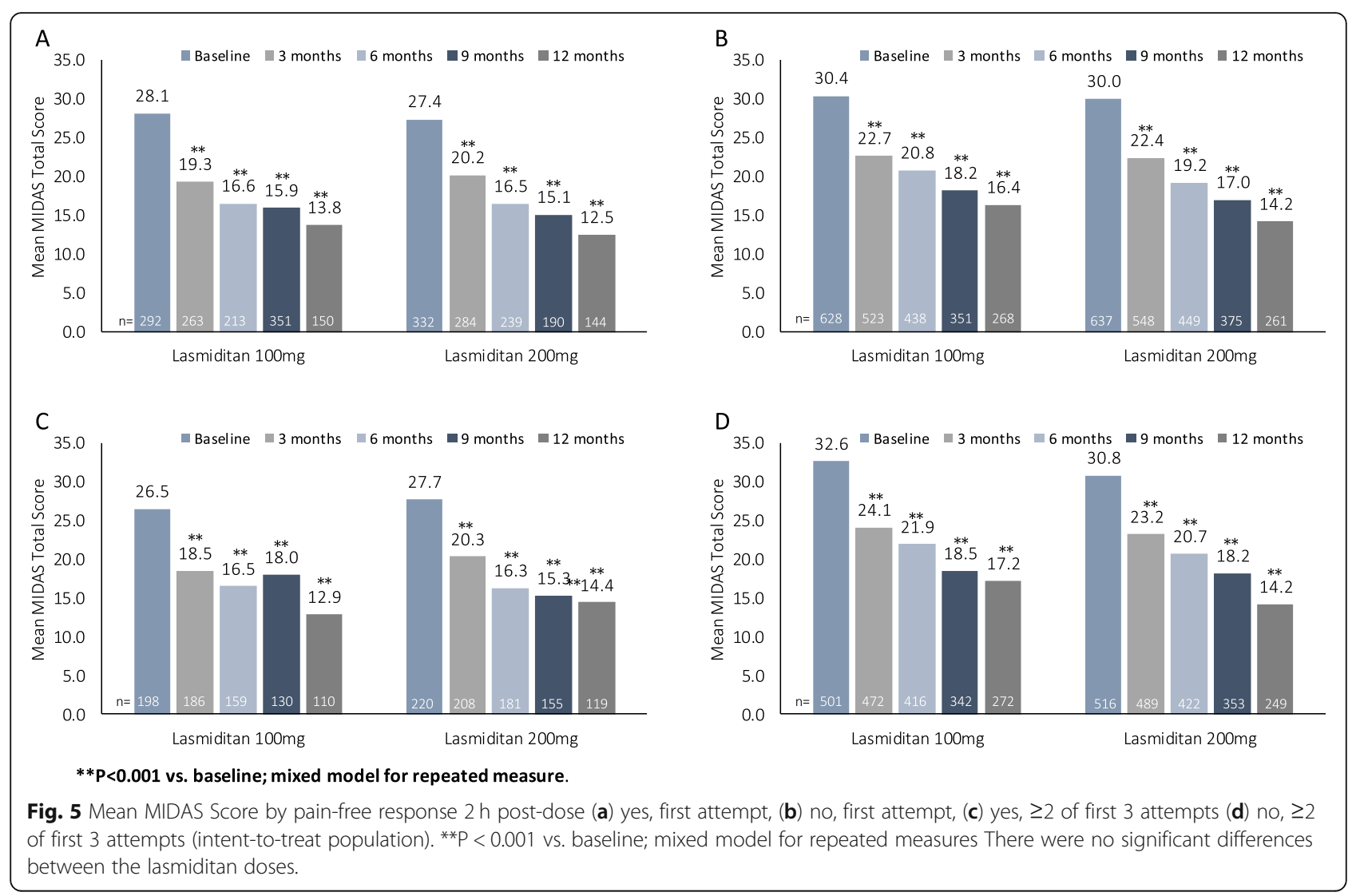

underestimate the severity of individual attacks or selectively recall more severe attacks, overall MIDAS scores were highly correlated with results from a daily diary [19]. Additionally, the MIDAS questionnaire was developed with a 3-month recall interval to balance the accuracy of self-reported information with a long enough recall interval to capture a representative amount of headache experience [18]. A limitation of the analysis of attack-related disability was that data were not available for all patients at all time points, as between 2 and $24 \mathrm{~h}$ after the first dose of study drug, patients were allowed to take a second dose of study drug for rescue or recurrence of headache, after which disability data relative to first dose were no longer collected. Finally, as part of the overall study design, patients were randomized to receive lasmiditan $100 \mathrm{mg}$ or $200 \mathrm{mg}$ and dose adjustment was not permitted, perhaps contributing to discontinuations for both efficacy and tolerability reasons.

In conclusion, the interim efficacy results presented here show progressive and clinically meaningful reductions in migraine-related disability during long-term dosing with lasmiditan. Patients with baseline severe versus moderate migraine-related disability showed greater reductions in disability over time. Response to lasmiditan per the MIDAS score was consistent across subgroups of baseline headache frequency, and of response to lasmiditan for initial treated attacks.

\section{Supplementary information}

Supplementary information accompanies this paper at https://doi.org/10. 1186/s10194-020-01088-4.

Additional file 1: The Migraine Disability Assessment (MIDAS)

Questionnaire [1-3]. Table S1. Change in mean days with headache over the last 3 months by completer status. Table S2. Change in mean headache pain intensity over the last 3 months by completer status. Table S3. Change in mean days with headache over the last 3 months by baseline number of migraine attacks. Table S4. Change in mean headache pain intensity during the past 3 months by baseline number of migraine attacks. Table S5. Change in mean days with headache over the past 3 months by pain-free response at $2 \mathrm{~h}$ post-dose for the first treated attack. Table S6. Change in mean headache pain intensity over the last 3 months by pain-free response at $2 \mathrm{~h}$ post-dose for the first treated attack. Table S7. Change in mean days with headache over the past 3 months by pain-free response at $2 \mathrm{~h}$ on $\geq 2$ of first 3 attempts yes/ no. Table S8 Change in mean headache pain intensity over the last 3 months by pain-free response at $2 \mathrm{~h}$ on $\geq 2$ of first 3 attempts yes/no.

\section{Acknowledgements}

Not applicable.

\section{Authors' contributions}

Dustin D Ruff oversaw the analyses. John H Krege, Louise Lombard, Li Shen Loo, Andrew Buchanan, and Dustin D Ruff were involved in study design. Li Shen Loo, Louise Lombard, and Thomas E Melby drafted the manuscript. 
Richard B Lipton, Dawn C Buse, John H Krege, Li Shen Loo, Louise Lombard, Andrew Buchanan, and Thomas E Melby were involved in interpretation of the data and in revision of the manuscript for important intellectual content. All authors approved the final draft of the manuscript.

\section{Funding}

The GLADIATOR study and the Rapid Service Fee were funded by Eli Lilly and Company. All authors had full access to all of the data in this study and take complete responsibility for the integrity of the data and accuracy of the data analysis.

\section{Availability of data and materials}

Lilly provides access to all individual participant data collected during the trial, after anonymization, with the exception of pharmacokinetic or genetic data. Data are available to request 6 months after the indication studied has been approved in the US and EU and after primary publication acceptance, whichever is later. No expiration date of data requests is currently set once data are made available. Access is provided after a proposal has been approved by an independent review committee identified for this purpose and after receipt of a signed data sharing agreement. Data and documents, including the study protocol, statistical analysis plan, clinical study report, and blank or annotated case report forms, will be provided in a secure data sharing environment for up to 2 years per proposal. For details on submitting a request, see the instructions provided at www. clinicalstudydatarequest.com.

\section{Ethics approval and consent to participate}

All participants provided written informed consent. The study was conducted in compliance with the International Council for Harmonisation principles of Good Clinical Practice. Ethics review boards approved the study protocol and the informed consent form prior to study commencement.

\section{Consent for publication}

All named authors meet the International Committee of Medical Journal Editors (ICMJE) criteria for authorship for this article, take responsibility for the integrity of the work as a whole, and have given their approval for this version to be published.

\section{Competing interests}

Richard B Lipton has received consultant fees, honoraria, and/or research grants from Alder, Allergan, Inc., Amgen, Biohaven, Dr. Reddy's Laboratories, eNeura, electroCore, Eli Lilly and Company, Novartis, Teva, and Trigemina. He has stock options in eNeura and Biohaven. Dawn C Buse has received grant support and honoraria from Allergan, Amgen/Novartis, Biohaven, Dr. Reddy's Laboratories/Promeius, Eli Lilly and Company, and Teva. Louise Lombard, Dustin D Ruff, John H Krege, Li Shen Loo, and Andrew Buchanan were employees and minor stockholders of Eli Lilly and Company. Thomas E Melby was an employee of Syneos Health, Inc., under contract to Eli Lilly and Company.

\section{Author details}

'Montefiore Medical Center, Bronx, NY, USA. ²Department of Neurology, Albert Einstein College of Medicine, Bronx, NY, USA. ${ }^{3}$ Eli Lilly and Company, Indianapolis, IN, USA. ${ }^{4}$ Syneos Health, Inc, Morrisville, NC, USA.

\section{Received: 3 December 2019 Accepted: 7 February 2020} Published online: 24 February 2020

\section{References}

1. Buse DC, Loder EW, Gorman JA, Stewart WF, Reed ML, Fanning KM et al (2013) Sex differences in the prevalence, symptoms, and associated features of migraine, probable migraine and other severe headache: results of the American Migraine Prevalence and Prevention (AMPP) study. Headache 53: 1278-1299

2. Lipton RB, Bigal ME, Diamond M, Freitag F, Reed ML, Stewart WF (2007) Migraine prevalence, disease burden, and the need for preventive therapy. Neurology 68:343-349

3. Lipton RB, Stewart WF, Scher AL (2001) Epidemiology and economic impact of migraine. Curr Med Res Opin 17(Suppl 1):S4-s12

4. (2017) Global, regional, and national incidence, prevalence, and years lived with disability for 328 diseases and injuries for 195 countries, 1990-2016: a systematic analysis for the Global Burden of Disease Study 2016. Lancet 390: 1211-1259

5. Steiner TJ, Stovner LJ, Vos T, Jensen R, Katsarava Z (2018) Migraine is first cause of disability in under 50s: will health politicians now take notice? J Headache Pain 19:17

6. Nelson DL, Phebus LA, Johnson KW, Wainscott DB, Cohen ML, Calligaro DO et al (2010) Preclinical pharmacological profile of the selective 5-HT1F receptor agonist lasmiditan. Cephalalgia 30:1159-1169

7. Rubio-Beltran E, Labastida-Ramirez A, Haanes KA, van den Bogaerdt A, Bogers AJJC, Zanelli E et al (2019) Characterization of binding, functional activity and contractile responses of the selective 5-HT1F receptor agonist lasmiditan. Br J Pharmacol. https://doi.org/10.1111/bph.14832

8. Capi M, De AF, Lionetto L, Gentile G, Cipolla F, Negro A et al (2017) Lasmiditan for the treatment of migraine. Expert Opin Investig Drugs 26:227-234

9. Reuter U, Israel H, Neeb L (2015) The pharmacological profile and clinical prospects of the oral 5-HT1F receptor agonist lasmiditan in the acute treatment of migraine. Ther Adv Neurol Disord 8:46-54

10. Rubio-Beltran E, Labastida-Ramirez A, Villalon CM, MaassenVanDenBrink A (2018) Is selective 5-HT1F receptor agonism an entity apart from that of the triptans in antimigraine therapy? Pharmacol Ther 186:88-97

11. Kuca B, Silberstein SD, Wietecha L, Berg PH, Dozier G, Lipton RB (2018) Lasmiditan is an effective acute treatment for migraine: a phase 3 randomized study. Neurology 91:e2222-e2232

12. Goadsby PJ, Wietecha LA, Dennehy EB, Kuca B, Case MG, Aurora SK et al (2019) Phase 3 randomized, placebo-controlled, double-blind study of lasmiditan for acute treatment of migraine. Brain 142:1894-1904

13. Krege JH, Rizzoli PB, Liffick E, Doty EG, Dowsett SA, Wang J et al (2019) Safety findings from phase 3 lasmiditan studies for acute treatment of migraine: results from SAMURAI and SPARTAN. Cephalalgia 39:957-966

14. Brandes JL, Klise S, Krege JH, Case M, Khanna R, Vasudeva R et al (2019) Interim results of a prospective, randomized, open-label, phase 3 study of the long-term safety and efficacy of lasmiditan for acute treatment of migraine (the GLADIATOR study). Cephalalgia 39:1343-1357

15. The International Classification of Headache Disorders: 2nd edition. (2004) Cephalalgia : an international journal of headache 24:9-160

16. Goff DC Jr, Lloyd-Jones DM, Bennett G, Coady S, D'Agostino RB, Gibbons R et al (2014) 2013 ACC/AHA guideline on the assessment of cardiovascular risk: a report of the American College of Cardiology/American Heart Association task force on practice guidelines. Circulation 129:S49-S73

17. Stewart WF, Lipton RB, Kolodner K, Liberman J, Sawyer J (1999) Reliability of the migraine disability assessment score in a population-based sample of headache sufferers. Cephalalgia 19:107-114

18. Stewart WF, Lipton RB, Dowson AJ, Sawyer J (2001) Development and testing of the migraine disability assessment (MIDAS) questionnaire to assess headache-related disability. Neurology 56:S20-\$28

19. Stewart WF, Lipton RB, Kolodner KB, Sawyer J, Lee C, Liberman JN (2000) Validity of the migraine disability assessment (MIDAS) score in comparison to a diary-based measure in a population sample of migraine sufferers. Pain 88:41-52

20. Tfelt-Hansen P, Pascual J, Ramadan N, Dahlof C, D'Amico D, Diener HC et al (2012) Guidelines for controlled trials of drugs in migraine: third edition. A guide for investigators. Cephalalgia 32:6-38

21. Lipton RB, Desai P, Sapra S, Buse DC, Fanning KM, Reed ML (2017) How much change in headache-related Diability is clinically meaningful? Estimating meaningful within person change in MIDAS using data from the AMPP study. Headache 57:165-166

22. Lipton RB, Stewart WF, Sawyer J, Edmeads JG (2001) Clinical utility of an instrument assessing migraine disability: the migraine disability assessment (MIDAS) questionnaire. Headache 41:854-861

23. Cady R, O'Carroll P, Dexter K, Freitag F, Shade CL (2014) SumaRT/nap vs naproxen sodium in treatment and disease modification of migraine: a pilot study. Headache 54:67-79

24. Otsuka N, Sakai F, Igaya M, Igarashi H, Shirataka M (2004) MIDAS assessments of migraine management, including the use of Triptans, in Japan. Headache Care 1:115-121

25. Pascual J, Falk R, Docekal R, Prusinski A, Jelencsik J, Cabarrocas X et al (2001) Tolerability and efficacy of almotriptan in the long-term treatment of migraine. Eur Neurol 45:206-213

26. Dowson AJ, Charlesworth BR, Green J, Farkkila M, Diener HC, Hansen SB et al (2005) Zolmitriptan nasal spray exhibits good long-term safety and tolerability in migraine: results of the INDEX trial. Headache 45:17-24 
27. Diamond S, Freitag FG, Diamond ML (2008) Open-label trial of frovatriptan $2.5 \mathrm{mg}$ oral tablets in subjects with high frequency of migraine. Headache 48:S50-S51

28. Connor KM, Aurora SK, Loeys T, Ashina M, Jones C, Giezek H et al (2011) Long-term tolerability of telcagepant for acute treatment of migraine in a randomized trial. Headache 51:73-84

29. Serrano D, Lipton RB, Scher Al, Reed ML, Stewart WBF, Adams AM et al (2017) Fluctuations in episodic and chronic migraine status over the course of 1 year: implications for diagnosis, treatment and clinical trial design. J Headache Pain 18:101

30. Stewart WF, Wood GC, Razzaghi H, Reed ML, Lipton RB (2008) Work impact of migraine headaches. J Occup Environ Med 50:736-745

31. Hawkins K, Wang S, Rupnow MF (2007) Indirect cost burden of migraine in the United States. J Occup Environ Med 49:368-374

32. Stewart WF, Wood GC, Manack A, Varon SF, Buse DC, Lipton RB (2010)

Employment and work impact of chronic migraine and episodic migraine. J Occup Environ Med 52:8-14

33. Bureau of Labor Statistics. (10-4-2019). Economic News Release: Average hourly and weekly earnings of all employees on private nonfarm payrolls by industry sector, seasonally adjusted. Table B-3, United States Department of Labor. 10-22-2019

34. National Research Council (US) Panel on Handling Missing Data in Clinical Trials. The Prevention and Treatment of Missing Data in Clinical Trials. Washington (DC): National Academies Press (US): 2010

35. The long-term tolerability and efficacy of oral zolmitriptan (Zoming, 311 C90) in the acute treatment of migraine. An international study. The International 311C90 Long-term Study Group (1998) Headache 38:173-183

\section{Publisher's Note}

Springer Nature remains neutral with regard to jurisdictional claims in published maps and institutional affiliations.

Ready to submit your research? Choose BMC and benefit from:

- fast, convenient online submission

- thorough peer review by experienced researchers in your field

- rapid publication on acceptance

- support for research data, including large and complex data types

- gold Open Access which fosters wider collaboration and increased citations

- maximum visibility for your research: over $100 \mathrm{M}$ website views per year

At $\mathrm{BMC}$, research is always in progress.

Learn more biomedcentral.com/submissions 